\title{
Fatty acid composition as a parameter of using vegetable oils for biofuel production
}

The aim of the study was to show the validity of determining the quality of oils intendent for the biofuels production. One of the main discriminant that should be used to assess the suitability of oil raw materials for the fuel purposes is the composition of fatty acids. The research was conducted on 13 different samples of vegetable oils, that were cold-pressed from the seeds of various species, including rape, camelina, flax (light and dark), mustard, milk thistle, hemp, evening primrose oil, amaranth, sunflower, soybean, and cumin. The analysis of the fatty acid composition showed significant differences between the analysed oil samples, both within the species and varieties of oilseeds. The results indicate the need for continuous quality control of oils and fats led to the production of biodiesel in the small households and large commercial enterprises, because as it was indicated by the analysis of fatty acids composition rape seeds of different varieties are characterized by the diverse quality.

Key words: vegetable oils, quality, fatty acids composition, biofuels production

\section{Introduction}

The term biodiesel is defined as the fatty acid alkyl monoesters derived from the renewable sources, such as edible and non-edible vegetable oils and animal fats [1]. The availability of oil-based raw material is dependent on the regional geography, native soil, climate and vegetation [2]. On the other hand, the main factors determining the biodiesel properties are: an oil quality [3], oil refinement (for example pretreatment step), conditions of transesterification and quality of phases in the purification step [4]. Among the presented factors, the content and quality of oil intendent for the biodiesel production, seems to be one of the most important. Edible and non-edible oils are characterized by the different oil seed content ( $w t \%)$. In case of the first group, content of this constitute varies for the seeds of rapeseed between 38-46 wt $\%$, cameline approx. 32-36.0 wt $\%$, milk thistle $20-35 \mathrm{wt} \%$, evening primrose $18-25 \mathrm{wt} \%$, hemp 25-35 wt $\%$, sunflower $25-35 \mathrm{wt} \%$ and soybean $15-20$ $w t \%$ [5-8]. On the other hand, the value of this discriminant in the non-edible plant oils was estimated on $65 \mathrm{wt} \%$ for nyamplung, between $43-59 \mathrm{wt} \%$ for jatropha, between $45-50 \mathrm{wt} \%$ for castor and between $40-60 \mathrm{wt} \%$ for rubber [9]. An oil molecule is composed of a gycerin backbone of three carbons, and each of these carbon atoms is attached to a long chain of fatty acids. The chemistry of oleaginous raw material is similar and is presented by the fatty acids with carbon atoms between 12-22. Some of these compounds are saturated and others are unsaturated. The number of the double bounds determines the level of unsaturation (one double bonds means mono-unsaturation, two or more polyunsaturation) [10]. The vegetable oils and animal fats are differentiated by saturated, mono- and poly-unsaturated share of these compounds. As Ramos et al. pointed the fatty acids profile of raw materials does not change during the transesterification process, that is way it is important to control this parameter [4]. Mittelbach and Remschmidt found that using biofuels characterized by the high content of glycerides, especially triglycerides, generates the formation of deposits at the injection nozzles and on the valves [11]. The same authors pointed that to achieve the biodiesel with a low presence of glycerides it is necessary to select appropriate reagents and reaction conditions. Cited authors, Pinzi et al. and Knothe and Steidley reported that the composition of these constitutes has an important impact during the estimation of some biodiesel discriminants, such as rate of FAME conversion, kinematic viscosity, stability of oxidation, cetane number, iodine number, cold filter plugging point, exhaust emission, lubricity and heat of combustion $[12,13]$. Richards et al. reported that the saturated fatty acids, having a natural preference for the first and third positions in the molecules of triglyceride, were transestrificated at the beginning of the process, while during the reaction progression the amount of unsaturated fatty acids esters increased [14]. Moreover, Pinzi et al., analysing the influence of vegetable oils fatty acid composition on the reaction temperature and glycerides conversion to the biodiesel during the transesterification, found that the conversion of mono-glycerides in FAME took place faster in case of the oils characterized by the higher degree of unsaturation (for example sunflower oil), then for these the most saturated (for example palm oil and maize oil) [15]. What is more, the cited authors reported that the optimal reaction temperature increased with a mean chain length increase and a number of polyunsaturated bonds decrease.

The main raw material for the biodiesel production in the most UE countries is rapeseed. However, is worth to mention that the seeds currently used in the oil manufacturing industry are a mixture of several winter varieties which do not guarantee a stable quality of the obtained oils, what affects the economic aspect of production. The same situation is observed in case of the other seed species, that are cultivated in other countries and continents. Therefore, it is so important to carry out a continuous control of the oil seeds quality. What is more, it is believed that estimating the fatty acids profile will allow to quickly verify the suitability on the individual plant oil for the biofuels production and thus let to avoid conducting other costly and timeconsuming and chemical analysis. Taking into account the above the aim of the study was to show the validity of determining the fatty acids composition of the different oleaginous plant oils. 


\section{Material and analytical methods}

\subsection{Material}

The raw material was presented by the group of vegetable oils, among others, oils pressed from the seeds of spring and winter varieties of rape, camelina, light and dark flax, mustard, milk thistle, hemp, evening primrose oil, amaranth, sunflower, soybean, and black seed.

\subsection{Analytical methods}

The composition of fatty acids in oils was determined according to the Polish Standard PN-EN ISO 12966-2:2011 [16] using the methyl esters that had been previously prepared as described by Zadernowski and Sosulski [17]. The quality analysis of fatty acids was performed on a GC 8000 FISONS series gas chromatograph with a flame-ion detector and a DB-225 type column $(30 \mathrm{~m} \times 0.25 \mathrm{~mm} \times 0.15$ $\mu \mathrm{m})$ and helium as a carrier gas. Fatty acids were identified based on the retention times determined for fatty acid models. Obtained results of researches were presented as the arithmetic mean (from three replicates).

\section{Results and discussion}

The conducted analysis of the fatty acids composition indicated on the significant differences in the profile of these compounds. The shares of individual fatty acids in the samples of two rapeseed varieties and two flax samples were diverse. Tańska et al. having analysed the fatty acids composition of three different varieties of rapeseed (winter hybrid variety Pomorzanin, winter pollinated variety Kana and spring pollinated variety Bios) also found differences in the profile of these compounds. The oil sample obtained from seeds of spring variety of rapeseed, in comparison to the winter varieties, was characterized by the lower share of oleic acid, while higher linolenic acid (Table 1).

The fatty acids composition of the oils obtained from the seeds of the different plant species was also differential. The most noticeable differences were found in case of the palmitic acid, oleic acid, linoleic acid, alfa-linolenic and gamma-linolenic acids, and eicosenic acid (Table 1).

The highest share of palmitic acid was noticed in the amaranthus oil $(19.56 \%)$, while the lowest in the sample of mustard oil $(3.85 \%)$. The high concentration of that compound was also found in the oil samples of soybean and black seed, while for the other 10 samples the share of palmitic acid did not exceed $10 \%$. One the other hand, the share of palmitooleic acid for the all analysed samples was below $0.3 \%$, while the stearic acids below $5.5 \%$.

One of the fatty acids, that most differentiated the analysed oil samples were oleic acid. Its share ranged from $6.75 \%$ for the evening primrose oil to $65.38 \%$ for the mustard oil. The rapeseed oils were also characterized by the high concentration of that compound $(>59 \%)$. In the other 3 samples (cameline oil, dark flax oil and hemp oil) the share of oleic acid was almost on a similar level (approx. $15-19 \%$ ), while in the other 4 (light flax oil, amaranthus oil, soybean oil and black seed oil) it was about $22 \%$. The last 2 samples of the milk thistle and sunflower oils were characterized by the, respectively, 28.42 and $31.96 \%$ share of that fatty acid (Table 1).

Table 1 . The composition of fatty acids of analyzed vegetable oil (\%)

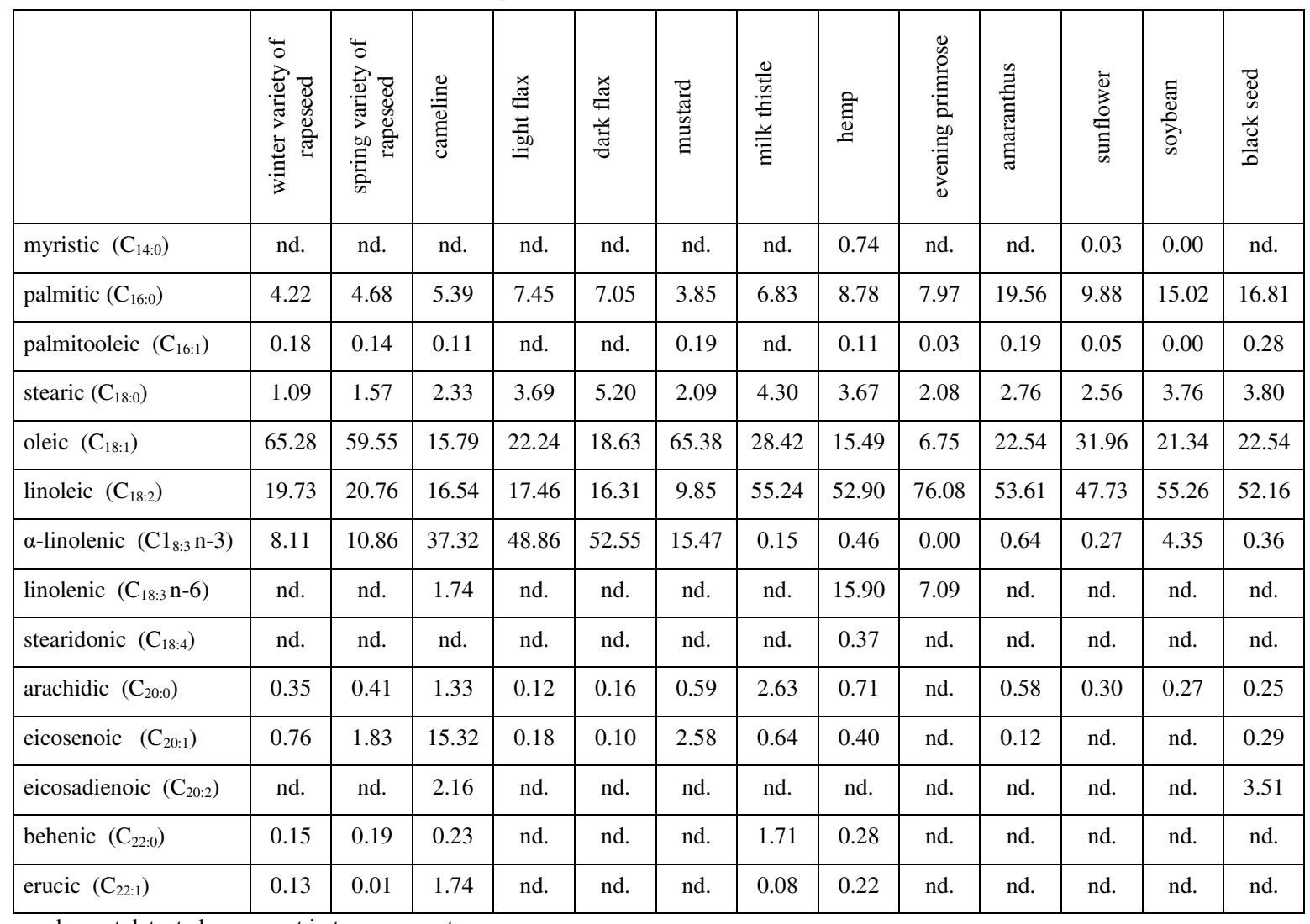

nd. - not detected or present in trace amounts 
Taking into the consideration the share of main polyunsaturated fatty acids, linoleic and alfa-linolenic, it was impossible to unequivocally state, which of them dominated in the analysed oils. Among the 13 samples of oils, 9 of them (oils of the two rapeseed varieties, milk thistle, hemp, evening primrose, amaranthus, sunflower, soybean and black seed) were characterized by the higher share of the linoleic acid. The concentration of that compound ranged from $9.85 \%$ for the mustard oil to $76.08 \%$ for the evening primrose oil. One the other hand, other 4 samples were characterized by the higher share of alfa-linolenic acid, in comparison to linoleic share. That group of oils was presented by the cameline, light and dark flax and mustard oils. The shares of that compound in the mentioned samples were from 15.47 to $52.55 \%$. One the other hand, the evening primrose sample was characterized by the trace amount of that compound, while in the other 5 samples (milk thistle oil, hemp oil, amaranthus oil, sunflower oil and black seed oil) the share of alfa-linolenic fatty acids did not exceed $1 \%$ and in the next 3 ones (two sample of rapeseed oil and soybean oil) $11 \%$. Moreover, the oils of cameline, hemp and evening primrose seeds were characterized by the presence of the gamma-linolenic fatty acids. The highest share of that compound was noticed in the hemp oil, which was also the only sample with the presence of the stearidonic fatty acids (Table 1).

The share of arachidonic fatty acid did not exceed $1 \%$ for 10 of the analysed samples, while the trace amount was observed in the evening primrose oil. The oils of cameline and milk thistle were characterized by the, respectively 1.33 and $2.63 \%$ share of that compound.
In case of the eicosenoic fatty acid, it was found that the cameline oil was characterized by the significant higher share of that compound (15.32\%), while in the other 9 samples the concentration of that fatty acid did not exceed $2.6 \%$, and in the last 3 samples its amount was trace.

Among the 13 oil samples only 2 of them - the cameline oil and black seed oil, were characterized by the presence of the eicosadienoic fatty acid, while the behenic and erucic fatty acids were noticed in the 5 analysed oils ( 2 rapeseed oil samples, cameline oil, milk thistle oil and hemp oil). The concentration of these compounds in the other samples was trace (Table 1).

The total share of saturated fatty acids, represented by the myristic, palmitic, stearic, arachidic and behenic fatty acids were differentiated. The higher concentration of these compound was observed for the amaranthus oil $(22.90 \%)$, black seed oil (20.86\%) and soybean oil $(19.05 \%)$, while the lower for the both samples of rapeseed (approx. 5.8\%) and for the mustard oil (6.53\%) (Table 2).

One the other hand, the total share of the palmitooleic, oleic and erucic fatty acids, that belong to the group of monounsaturated fatty acids, was significantly higher in the rapeseed and mustard samples. The lowest total share of listed fatty acids were found in the evening primrose oil, that in turn was characterized by the highest total share of the polyunsaturated fatty acids $(83.17 \%)$. The increased share of that fatty acids group was also noticed for the oils of cameline (73.08\%), hemp (70.03\%), dark and light flax (respectively, 66.50 and $68.96 \%$ ). In turn, the samples of rapeseed and mustard were characterized by the lower (approx. $27 \%$ ) concentration of these compounds (Table 2).

Table 2. Total share of the individual groups of fatty acids (\%)

\begin{tabular}{|c|c|c|c|c|c|c|c|c|c|c|c|c|c|}
\hline & 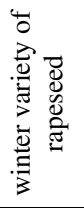 & 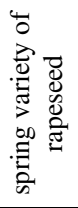 & $\begin{array}{l}\stackrel{\mathscr{\Xi}}{\Xi} \\
\stackrel{\Xi}{\Xi}\end{array}$ & 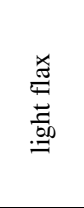 & 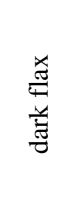 & $\begin{array}{l}\bar{\Xi} \\
\stackrel{\vec{J}}{0} \\
\vec{\Xi}\end{array}$ & 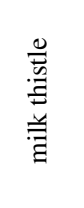 & 宅 & 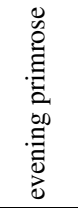 & 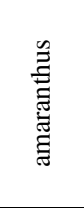 & 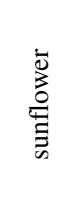 & 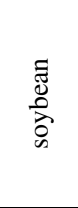 & 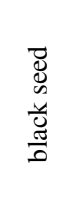 \\
\hline $\begin{array}{l}\text { total share of saturated fatty } \\
\text { acids }\end{array}$ & 5.81 & 5.85 & 9.28 & 11.26 & 12.41 & 6.53 & 15.47 & 14.17 & 10.05 & 22.90 & 12.77 & 19.05 & 20.86 \\
\hline $\begin{array}{l}\text { total share of monounsatu- } \\
\text { rated fatty acids }\end{array}$ & 65.59 & 67.70 & 17.64 & 22.24 & 18.63 & 65.57 & 28.50 & 15.81 & 6.78 & 22.73 & 32.01 & 21.34 & 22.82 \\
\hline $\begin{array}{l}\text { total share of polyunsaturat- } \\
\text { ed fatty acids }\end{array}$ & 28.60 & 26.45 & 73.08 & 66.50 & 68.96 & 27.90 & 56.03 & 70.03 & 83.17 & 54.37 & 48.00 & 59.61 & 56.32 \\
\hline
\end{tabular}

During analysing the influence of fatty acids composition of the raw material properties for the biofuel production, it should be remembered that there is no single fatty acid that is responsible for any particular fuel characteristics. The physico-chemical properties of the biodiesel dependent on the fatty acid structural features, among other, a chain length, degree of unsaturation and branching of the chain [18].

High amounts mono-, di, and triglycerides in fuels cause that these products are prone to the coking and may lead to the formation of deposits to the injector nozzles, pistons and valves. Share of these compounds in thetransesterified oil - biodiesel has an important influence on its yield, or as Vicente at al. stated on the purity of biodiesel [19]. Pinzi et al., analysing, effect of the fatty acid composition of vegetable oils on the biodiesel optimization found that oils with a high unsaturated fatty acids content shown a proportional dependence between the catalyst concentration and yield [15]. Moreover, cited authors found that the fatty acid chain length influences the biodiesel conversion. Oils characterized by the longer fatty acid chains needed half of the re- 
quested reaction time, compared to samples with the shorter fatty acids chains.

One of the discriminant that determine the number of double bonds (unsaturated ones) presented in the oil is an iodine number [20]. Islam et al. reported, that the higher share of unsaturated fatty acid in raw material, the higher value of that discriminant [18]. Altun found that biodiesel characterized by the lowest iodine number leads to the highest cetane number and as a consequence, reduces nitrogen oxides emissions [21].

The ignition quality of biofuel is related to the cetane number, that determines the ability of the fuel to ignite quickly after being injected - a higher value indicates a getter ignition quality of fuel [22]. Value of that discriminant decreases with a decreasing chain length, increasing branching, and increased saturation in the fatty acid chain [23]. As cited author found the higher cetane number, the better quality of ignition whereas the saturated esters, which are advantageous for mentioned discriminant possess poor cold-flow properties. The biofuels produced from the raw material characterized by the high share of the polyunsaturated fatty acids let to obtain the esters improving a coldflow, due to their low melting point, what is considered as desirable. However, a high amount of polyunsaturated fatty esters contributes (undesirable for fuel) the lower cetan number and oxidative stability. The oxidation of biodiesel may induce the polymerisation of esters and form insoluble gums, which contribute to clogging of the fuel filters [24].

Muniyappa et al., analysing possibility of using the soybean and tallow oil for biodiesel production, found that that methyl esters from the beef tallow oil were characterized by the high cold point, what was involved with the high concentration of saturated fatty acid methyl esters [25]. Mittelbach and Remschmidt, Wang et al. and Chuah et al. explained that during the biodiesel cooling, the first fraction to precipitate is the stearic and palmitic methyl esters [11, $26,27]$. What is more, these components constitute a substantial share of material that are recovered from clogged biodiesel fuel filters. Moreover, Knothe and Steideley, analysing the dependence of biodiesel viscosity on the structure of fatty acid alkyl esters, found that with an increasing chain length and saturation of fatty acids the viscosity of obtained esters increased [13]. The cited authors also reported that cis double bonds contribute to a reduction of esters viscosity, while trans ones display this parameter similar to their saturated counterparts.

\section{Conclusions}

During the selection of a suitable raw material for the biofuel production, the attention should not be paid only on the oil content, but also on its quality. One of the discriminant, which lets to quickly verify the usefulness of individual raw material is the composition of fatty acids. As assessed, such oil samples as the evening primrose oil, cameline oil, hemp oil, light and dark oils, that were characterized by the increased share of the polyunsaturated fatty acids should not be used as a self-contained fuel, due to the low oxidative stability. On the other hand, biofuels that would be produced from oils with a high share of saturated fatty acids, such as amaranthus oil, black seed oil would be characterized by high cold point.

[9] ATABANI, A.E., SILITONGA, A.S., BADRUDDIN, I.A. et al. A comprehensive review in biodiesel as an alternative Energy resource and its characteristics. Renewable and Sustainable Energy Reviews. 2012, 16(4), 2070-2093.

[10] US DEPARTMENT OF ENERGY. Biodiesel handling and use quidelines, US Department of Energy, Energy efficiency and renewable energy, Third edition. September 2006.

[11] MITTELBACH, M., REMSCHMIDT, C. Biodiesel: The Comprehensive Handbook Boersedruck GmbH, 2004, Vienna, Austria.

[12] PINZI, S., GARCIA, I.L., LOPEZ-GIMENEZ, F.J. et al. The ideal vegetable oil-based biodiesel composition: a review of social, economical and technical implications. Energy \& Fuels. 2009, 23(5), 2325-2341.

[13] KNOTHE, G., STEIDLEY, K.R. Kinematic viscosity of biodiesel fuel components and related compounds. Influence of compound structure and comparision to petrodiesel fuel components. Fuel. 2005, 84(9), 1059-1065.

[14] RICHARDS, A., WIJESUNDERA, C., PALMER, M., SALISBURY, P. PAOCS. 2002, Australian Workshop, Sydney.

[15] PINZI, S., GANDÍA, L.M., ARZAMENDI, G. et al. Influence of vegetable oils fatty acid composition on reaction temperature and glycerides conversion to biodiesel during transestrification. Bioresource Technology. 2011, 102(2), 1044-1050.

[16] PN-EN ISO 12966-2:2011. Animal and vegetable fats and oils - Analysis by gas chromatography of methyl esters of fatty acids. 
[17] ZADERNOWSKI, R., SOSULSKI, F. Composition of total lipids in rapeseed. Journal of American Oil Chemistry Society. 1978, 55(12), 870-872.

[18] ISLAM, M.A., AYOKO, G.A., BROWN, R. et al. Influence of fatty acid structure on fuel properties of algae derived biodiesel. Procedia Engineering. 2013, 56, 591-596.

[19] VICENTE, G., MARTINEZ, M., ARACIL, J. Optimisation of integrated biodiesel production Part I. A study of the biodiesel purity and yield. Bioresource Technology. 2007, 98(9), 1724-1733.

[20] ROCHA, M.V.P., LIMA DE MATOS, L.J.B., PINTO DE LIMA, L. et al. Ultrasound-assisted production of biodiesel and ethanol from spent coffee grounds. Bioresource Technology. 2014, 167, 343-348.

[21] ALTUN, S. Effect of the degree of unsaturation of biodiesel fuels on the exhaust emission of a diesel power generator. Fuel. 2014, 117(A), 450-457.

[22] ABBASI, S., DIWEKAR, U.M. Characterization and stochastic modeling of uncertainties in the biodiesel produc-
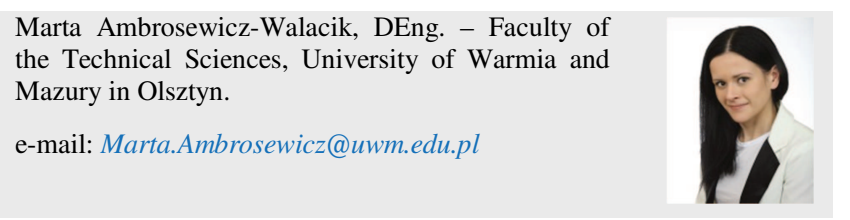

tion. Clean Technologies and Environmental Policy. 2014, 16(1), 79-94.

[23] KNOTHE, G. „Designer” biodiesel: optimalizing fatty ester composition to improve fuel properties. Energy \& Fuels. 2008, 22(2), 1358-1364.

[24] JAIN, S., SHARMA, M.P. Effect of metal contents on oxidation stability of biodiesel/diesel blends. Fuel. 2014, 116, 14-18.

[25] MUNIYAPPA, P.R., BRAMMER, S.C., NOUREDDINI, H. Improved conversion of plant oils and animal fats into biodiesel and co-product. Bioresource Technology. 1996, 56(1), 19-24.

[26] WANG, L.B., YU, H.Y., HE, X.H., LIU, R.Y. Influence of fatty acid composition of woody biodiesel plants on the fuel properties. Journal of Fuel Chemistry and Technology. 2012, 40(4), 397-404.

[27] CHUAH, L.F., YUSUP, S., AZIZ, A.R.A. et al. Influence of fatty acid content in non-edible oil for biodiesel properties. Clean Technologies and Environmental Policy. 2016, 18(2), 473-482.
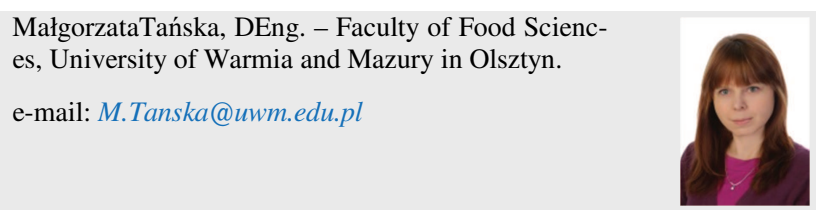

Marek Walacik, DEng. - Faculty of Geodesy, Geospatial and Civil Engineering, University of Warmia and Mazury in Olsztyn.

e-mail: Marek.Walacik@uwm.edu.pl 